Article

\title{
Costs of Demand Response from Residential Customers' Perspective
}

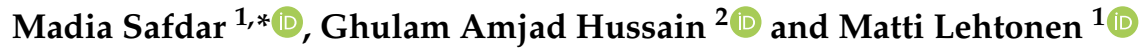 \\ 1 Department of Electrical Engineering and Automation, Aalto University, 02150 Espoo, Finland; \\ matti.lehtonen@aalto.fi \\ 2 Department of Electrical \& Computer Engineering, American University of Kuwait, Salmiya 13034, Kuwait; \\ ghussain@auk.edu.kw \\ * Correspondence: madia.safdar@aalto.fi
}

Received: 21 March 2019; Accepted: 26 April 2019; Published: 28 April 2019

\begin{abstract}
Electricity demand in a certain locality varies during the day, depending on weather conditions, daily life routines, or a social event in a town. During high/peak demands, expensive power plants are put into operation, which affects electricity prices. Moreover, power lines are overloaded. If generation capacity is insufficient, a blackout may result. Demand response (DR) programs are widely proposed in energy research to tackle these problems. Although the benefits of DR programs are well known, customer response levels to these programs is low. This is due to the small fraction of benefits they receive against the loss of comfort, lost leisure time, and other inconveniences. The objective of this work is to study DR costs from the customer perspective by considering these factors. A customer survey-based direct approach is used to evaluate the willingness of customers to accept (WTA) a certain compensation when shifting the load is adopted. Two different methods are used to calculate DR costs: percentage compensation, which customers are WTA, and one based on a macroeconomic model, which considers the dependency factor of customers on loads and hourly wage. A linear mathematical model is presented based on both these techniques. This study reveals that DR costs are much less than interruption costs paid by the utility company, and hence is in the best interests of all stakeholders, i.e., customers, utility company, and transmission company.
\end{abstract}

Keywords: Demand Response (DR); Customer Interruption Costs (CIC); DR Costs; Willingness to Pay (WTP); Willingness to Accept (WTA)

\section{Introduction}

In this era of fast lifestyle, electricity has become one of the most important human dependencies. We are dependent on electricity at every step of our life. Transportation, health facilities, telecommunication networks, electrical lighting, computers, and domestic automated appliances are some of the modern electrical loads without which life cannot be imagined [1]. As a result of high dependency on electricity, the demand for electricity production is also increasing day by day, which requires utility companies to increase their generation capacity to fulfill the desired demand [2]. Increasing demand causes peaks during certain hours of a day in electricity load curve [3], and this peak may have unbearable effects on power transmission lines, which are at a high risk of failure and losses due to overloading, which leads to power outages or blackouts [4].

The current solutions to the problem of irregular electricity demand is increasing generation capacities by adding new power plants, developing energy storage techniques and demand response (DR) [5]. The first two solutions are based on the idea of increasing supply to match the demand. However, this approach is not sustainable and is not affordable in all countries. Moreover, adding 
new conventional power plants is economically not preferred because they will match the demand during peak hours but may stay idle during off-peak hours and hence results in wasted capacity. Adding more renewable energy sources may not solve the problem due to their intermittent nature and low reliability [6,7]. Energy storage is considered to be one of the key components to match demand and supply in the future smart grid. However, bulk storage is still a challenge and is under research and development currently [8]. DR is the one of the solutions to match the supply with demand by managing the demand (shifting uninterruptible or schedulable loads) unlike the other solutions where supply is regulated to match the demand. The DR programs deal with peak events effectively by changing the demands to match the available generation, and help to prevent the network from overloading [9-11]. In this way, DR helps to avoid electricity outages or blackouts, increases savings in electricity bills, and raises responsibility awareness in customers [12-14]. The motivation for customers to participate in the DR program lies in the reduction of price volatility in electricity tariffs [15]. However, it requires certain compromises from customers to ensure continuous supply of electricity [16]. DR programs in the residential sector can be implemented in two ways, which are either through price-based, also known as indirect load control (ILC), and incentive-based techniques, also-called direct load control (DLC), and the customers are compensated accordingly [17-19]. In ILC, customers are encouraged to reduce their energy consumption based on electricity price patterns during off-peak and peak hours. Naturally, the electricity prices during peak hours are higher than the off-peak hours, due to the need for expensive power plants to be put on operation to meet the peak demand. This motivates customers to shift some of their non-critical loads to off-peak hours to save electricity cost [20]. In DLC, customers are offered incentives to participate in the DR programs while ensuring the scheduling, reduction, or disconnection loads whenever needed. The instantaneous demand and operating state of individual devices are managed using centralized controller, which conduct both decisions and control actions [21].

The residential sector accounts for 30-40\% of total energy consumed [22,23]. Hence, a huge potential lies in implementing DR programs for the residential sector to achieve the above objectives. Various DR programs have been proposed and evaluated in the literature [24-30]. The potential of DR programs is determined in terms of energy saving and peak shifting. Most of these programs claim to be effective in reducing the peaks by up to $35 \%$ and reduction in electricity bills by up to $10 \%$. In [31,32], the responsiveness of the customers in various DR programs is evaluated. Customers respond to a time-varying electricity tariff in ILC, but their response varies widely. Some results show that a high fraction of residential customers do not respond to the price signals. This may be due to the small fraction of benefits in their monetary budgets compared to various compromises they have to make including loss of comfort, loss of leisure time, loss of flexibility, etc. This research work fills this gap to evaluate such factors in terms of DR costs. Figure 1 lists different categories of DR costs faced by both the customer and the utility company $[33,34]$. The DR costs evaluated in this research through customer survey cover the two sub-categories highlighted blocks, i.e., discomfort costs and incentives. Both costs are correlated with each other, as the discomforts faced by the customers while participating in the DR programs should be compensated. Otherwise, the customers will lack motivation and will be less willing to participate in the DR programs. This study is beneficial for both the utility companies and domestic electricity users. A utility company may use the principles and methodology described in this article, for a certain locality or town to plan a DR program to avoid peak loading or interruption (in severe cases). These principles also provide a guide that highlights the risks and benefits to domestic customers to participate in DR programs.

The paper is organized as follows: Section 2 presents the methodology and steps adopted to determine the DR costs. Section 3 provides analysis of survey results and elaborates the costs calculated from it. Section 4 establishes a correlation and comparison between the calculated DR costs and the CICs. The last section, Section 5 , provides conclusions. 


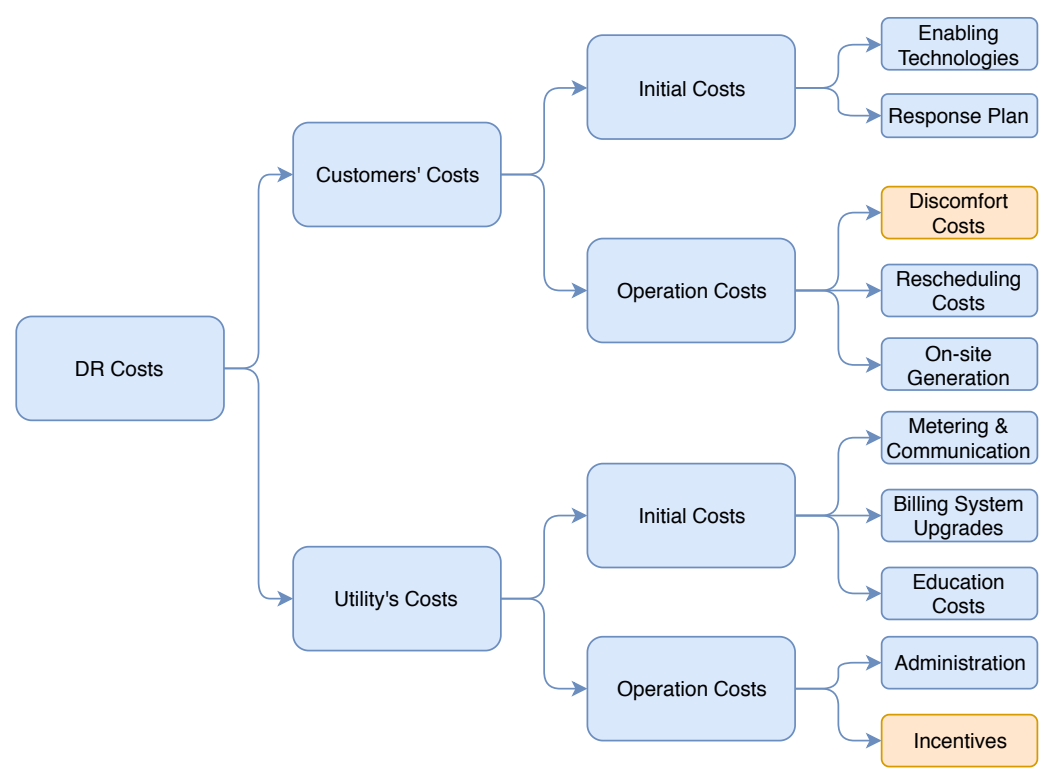

Figure 1. Classification of DR costs for utilities and consumers [33].

\section{Methodology}

\subsection{Daily Load Curve}

A daily load curve is drawn in Figure 2, which shows major electricity usage of an average household in Finland. During winter, the major load in a house is space heating, which can be clearly seen as a constant load during the day and rises around midnight. Other major loads such as water heater, cooking appliances, vacuum cleaner, and electric iron are used during certain hours of a day [35]. Therefore, it is in the best interest of power companies and end users to shift some of the non-critical loads to other hours of a day when electricity demand is almost stable.

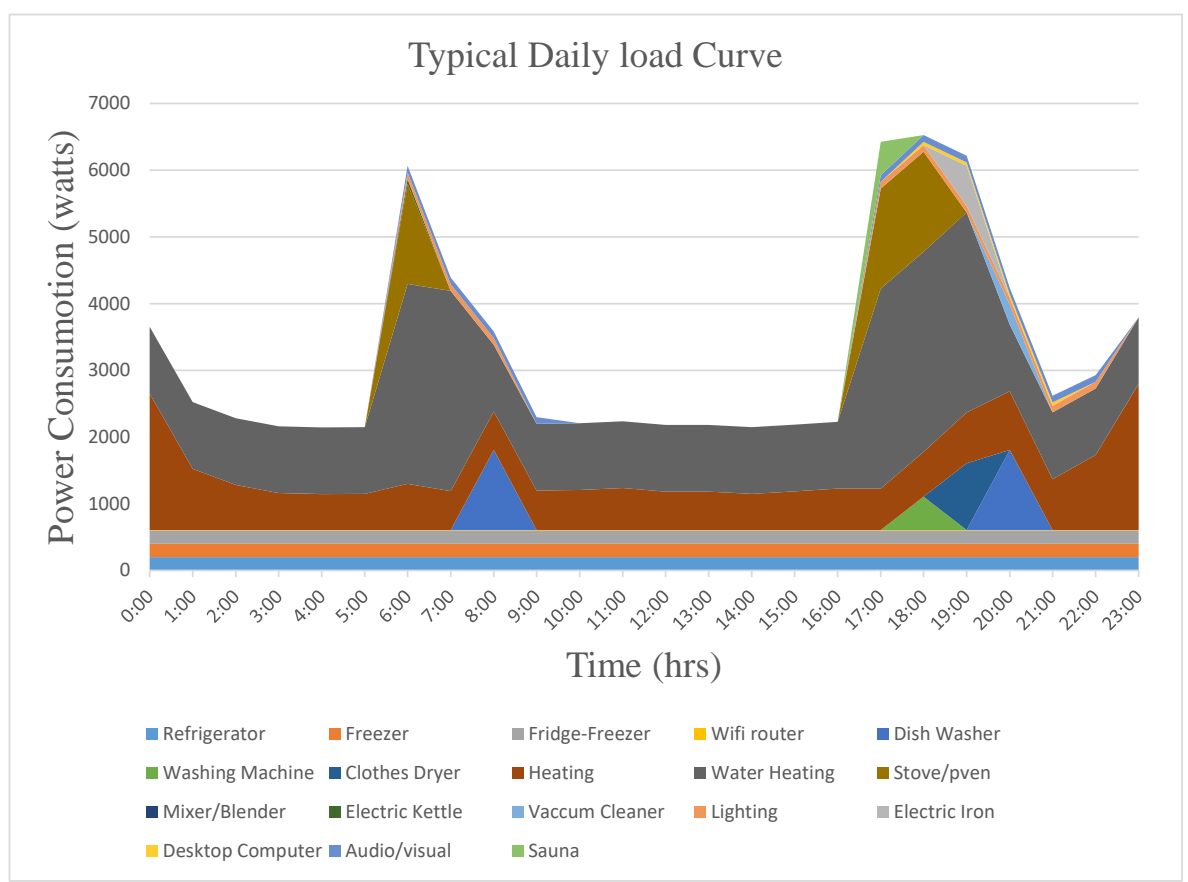

Figure 2. Daily load consumption curve of a typical house in Finland (24 h). 


\subsection{Direct and Indirect Cost Calculation Methods}

Various methods can be used to evaluate the costs of DR, broadly categorized as indirect analytical methods and direct approaches [36,37]. The indirect analytical methods are implemented using the data which is accessed easily on different sources such as electricity prices or tariff, annual electricity consumption of a country or locality, gross national product of a country and various other factors need to be considered [38]. In such analysis the DR costs are directly proportional to the customer damage functions (CDF). $\mathrm{CDF}$ is defined as the sufferings happened to the customers such as the economic losses due to the load shifting or as a result of electricity outages [39]. In direct approaches, customer surveys are conducted and data on the willingness of customers is collected by telephone calls, one-to-one interviews, or by online or paper-based questionnaire [40].

\subsection{Correlation between Customer Interruption Cost (CIC) and DR Cost}

Consequences faced by either interruption of electric supply to the customers or DLC can be very similar. For example:

- Food spoilage

- Restriction of leisure activities at home

- Restriction of working performance

- Data loss and reconfiguration of equipment

- Interruption of space heating or cooling, hence compromising the comfort levels

- Other inconvenience

A lot of work has been done previously to calculate cost of the direct load control approaches and electricity interruptions which provide basis for estimating the DR costs $[4,37,38,41-44]$. The customers were asked what kind of issues and losses they got in case of an interruption happened in the past. The interruptions were categorized based on the duration of outages such mas monetary interruptions (very short duration ) and non-monetary interruptions long durations and they were further subdivided into various categories. Empirically, interruption cost can be estimated by the following Equation (1).

$$
\mathrm{CIC}=\frac{\text { Total cost incurred due to interruption }}{\text { Total estimated energy not served during the interruption }}
$$

Customers willing to avoid interruption will be motivated to participate in the DR programs. The reference to these works is used in this research to calculate the costs of compensation to participate in DR programs.

\subsection{Procedure}

Complete procedure adopted in this research is summarized in the following steps:

1. A customer survey was conducted for 145 residential customers (sample questionnaire is given in Supplementary Materials. Customers were asked to show their willingness to shift, against each of their appliance along with the shifting duration. They were also asked percentage compensation on electricity bills they are willing to accept (WTA) in return. Hence, a WTA approach is adopted in this research. Shifting duration varied from $5 \mathrm{~min}$ to $600 \mathrm{~min}$. More details can be found in the survey questionnaire.

2. Survey results are given in Appendix A.1 which summarize the percentage shifting flexibility of each appliance against each shifting time interval.

3. From the percentage shifting flexibility, a more useful parameter, percentage power flexibility was calculated.

4. Average percentage compensation is calculated for all the houses. 
5. Average dependency factor for all the customers on electricity is calculated based on the shifting flexibility.

6. DR cost is calculated by using the average compensation percentage and dependency factor. Both are then compared with CIC.

7. The DR costs calculated above are then plotted as a function of shifting intervals to find a mathematical relationship.

\section{Customer Survey and DR Cost Calculation}

The survey given in Supplementary Materials was conducted for residential customers in Helsinki and Espoo area. A total of 145 houses participated in the survey. The data was processed in excel and the averaged survey results are given in Appendix A.1, which summarize the percentage of customers willing to participate in DR, or not willing, and percentage of appliances which are shiftable. 15 different most available domestic appliances were considered in this survey. Out of 145 customers, 12 were not willing to participate in the DR program, and the analysis was done for 133 houses.

In the customer survey, customers were asked to describe their expectation for compensation to be paid by the utility company as a result of participating in the DR programs and shifting some of their load during the time of needs. Hence, this cost includes the compensation for the loss of leisure time, loss of comforts and loss of freedom to use their appliances and carry on their daily activities according to their wishes.

\subsection{Sample Data Analysis}

The survey results provide information about how many customers are willing to shift (WTS) to a certain appliance for a specific shifting duration. Categorization of appliance into critical and non-critical, is completely dependent on customers' choice. The percentage ownership of an appliance is calculated by Equation (2). The results are given in the first column of Appendix A.1.

$$
\% \text { Ownership of an Appliance }=\frac{\text { Number of Customers with that Appliance }}{\text { Total No. of Customers Responded }} \times 100
$$

Percentage of customers who are WTS to a specific appliance for certain duration of time is calculated by Equation (3).

$$
\% \text { WTS }=\frac{\text { Customer WTS for specific duration }}{\text { Total Customers Responded }} \times 100
$$

For example, customers' WTS microwave oven for specific duration of time is given in Table 1 below.

Table 1. Inclination of customers to postpone operation of microwave oven vs. shifting interval.

\begin{tabular}{cc}
\hline Shift Duration (min) & \% Willingness to Shift \\
\hline 5 & $24 \%$ \\
15 & $12 \%$ \\
30 & $17 \%$ \\
60 & $4 \%$ \\
180 & $6 \%$ \\
300 & $2 \%$ \\
600 & $3 \%$ \\
\hline
\end{tabular}

It is also considered, if a customer is WTS a certain appliance for a certain duration for example $30 \mathrm{~min}$, the appliance is obviously shiftable for all the lower shift durations, i.e., $5 \mathrm{~min}$ and $15 \mathrm{~min}$ as well. Therefore, for the above table the percentage shifting flexibility is calculated based on this fact as given in Table 2. Percentage flexibility for all the appliances is calculated and given in Appendix A.2. 
Table 2. Percentage shift flexibility of microwave oven vs. shifting interval.

\begin{tabular}{cc}
\hline Shift Duration (min) & \% Percentage Flexibility \\
\hline 5 & $68 \%$ \\
15 & $44 \%$ \\
30 & $32 \%$ \\
60 & $15 \%$ \\
180 & $11 \%$ \\
300 & $5 \%$ \\
600 & $3 \%$ \\
\hline
\end{tabular}

\subsection{Average Flexibility of Appliances}

Flexibility is the measure of the consumer response to a tariff change or price signals. The following data summarizes the average flexibility percentage of home appliances as a function of shifted time intervals. Average flexibility of all the appliances for a specific shifting interval is calculated simply by taking an average of percentage flexibility of all the 15 appliances. For example, for 5 min shifting interval, the percentage flexibility of all the appliances for $5 \mathrm{~min}$ are added up and divided by the number of appliances, i.e., 15. This is done by adding all the entries in a column in Appendix A.2 and dividing by 15. Results are given in the last row of this Table and given in Table 3 . The results show that $83 \%$ of the loads can be shifted for $5 \mathrm{~min}$ which is quite a significant amount of load. When the shifting interval is extended to several hours, this percentage value drops. This obviously reflects human needs, comforts, and freedom. One can postpone a certain load for a short duration but eventually will be needing it after some time. Table 3 and Figure 3 explaining the average flexibility compromised by the customers is shown below.

Table 3. Average flexibility vs. shifting duration.

\begin{tabular}{cc}
\hline Shift Interval & Avg. Flexibility per Household for Specific Shifting Interval \\
\hline 5 & $83 \%$ \\
15 & $69 \%$ \\
30 & $61 \%$ \\
60 & $51 \%$ \\
180 & $34 \%$ \\
300 & $20 \%$ \\
600 & $11 \%$ \\
\hline
\end{tabular}

Figure 3 below shows the pattern of average flexibility with respect to shifting durations.

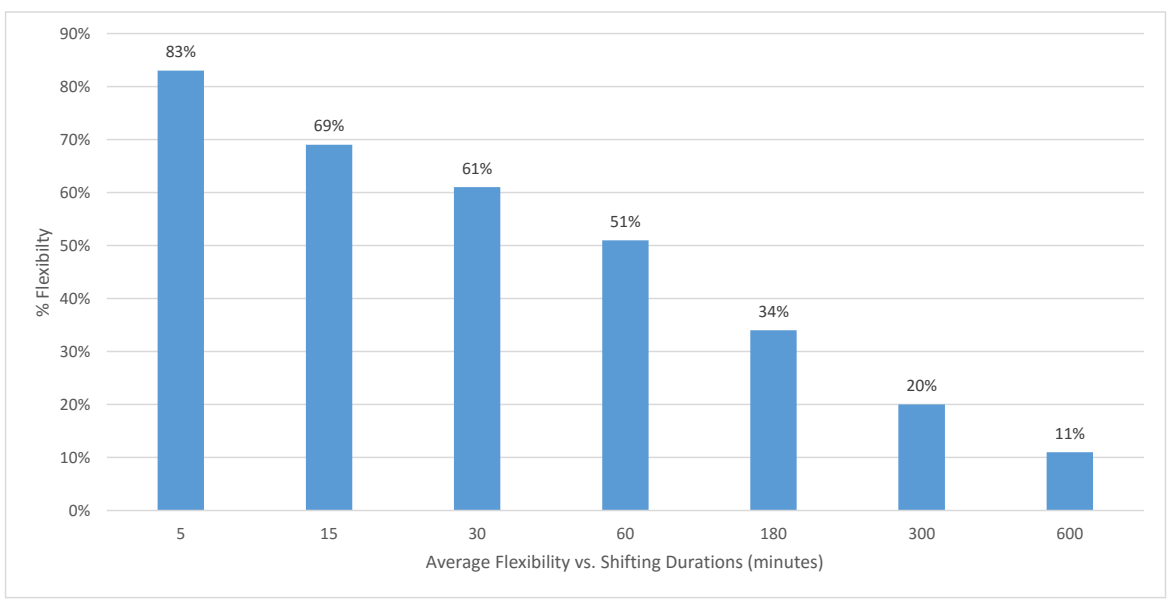

Figure 3. Average flexibility vs. shifting durations. 


\subsection{Reduction in Power Reduction Due to the Shifting of Domestic Appliances}

From the survey results, the percentage of flexibility of each device provides information about which devices are shiftable and to what extent. However, this information is insufficient from the utility company point of view, as additional information is needed for how much reduction in power consumption will be offered by the customer if they postpone the operation of a specific appliance during the peak hours. For this purpose, the power of each appliance needs to be incorporated as well. Therefore, in the following Figure 4, the percentage power-shifting capacity of each of the home appliances is determined and plotted versus shifting interval. This figure gives a holistic view of all the appliances' percentage power flexibilities. The percent power flexibility is calculated using Equation (4).

$$
\% \text { Power Shift Flex }=\frac{\text { Power Cons. of Appliance }}{\text { Total Power Cons per House }} \times \text { Average } \% \text { Flex of Appliance }
$$

The power-shifting potential of all the other appliances mentioned in the survey is shown in the following Figure 4, which gives clear understanding of the potential in power reduction of domestic appliances during the peak hours.

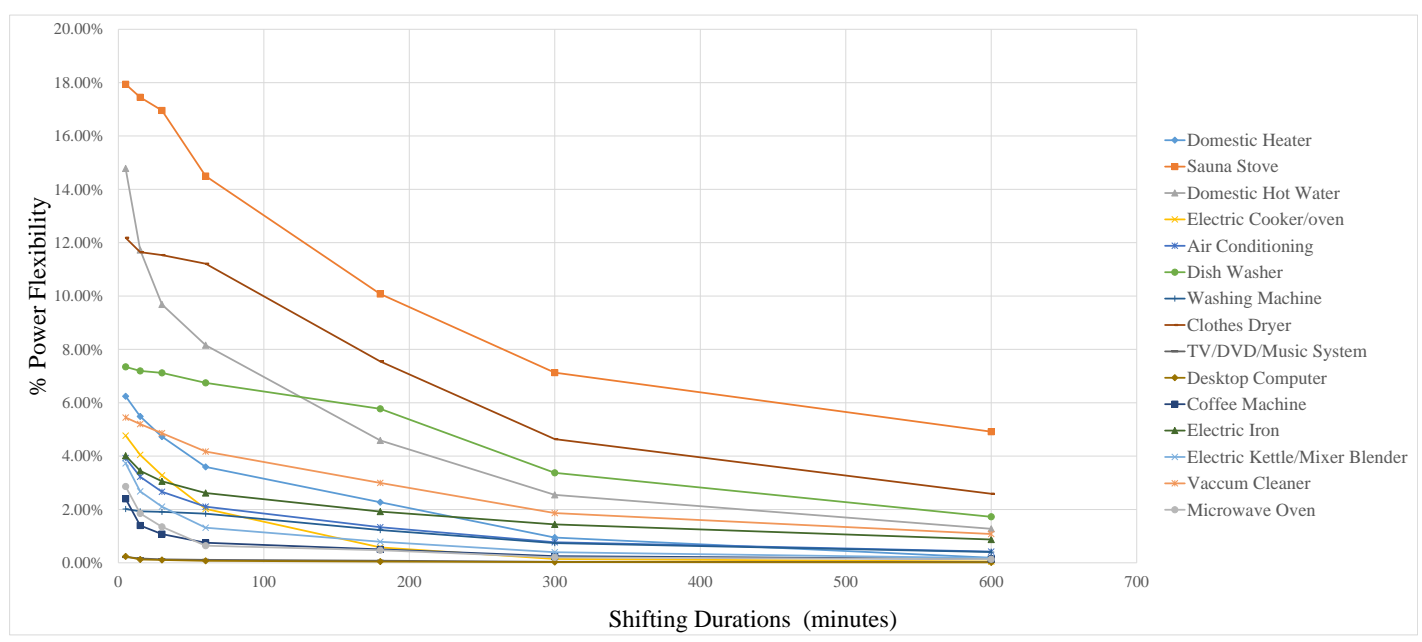

Figure 4. Percentage power reduction due to shifting of appliances w.r.t shifting intervals.

\subsection{Compensation Cost Calculation}

Compensation or incentive paid back to the customers involved in the DR program compensates for the lost utility. There is loss of comfort to the customer as a result of load shifting. The comfort requirements of customers vary widely. In the customer survey, customers were asked to indicate the time shifting duration for individual loads and that indicated the dependency and importance of individual equipment to a customer. Customers who indicated less shifting duration for a certain appliance, means that appliance is very critical/important for him/her and dependency of that customer on that appliance is high. Therefore, if he/she is asked to shift that appliance for a longer duration, he/she must be compensated more than others.

For instance, if someone is willing to postpone a certain appliance only for $5 \mathrm{~min}$ and the utility company asks for $1 \mathrm{~h}$ shift, that means the value of the use of this equipment is $1 \mathrm{~h}$ divided by $5 \mathrm{~min}$ to the customer, i.e., 12 . So it is 12 times more valuable than the basic value of $1 \mathrm{~h}$. Therefore, this customer must be compensated 12 times more than another customer who can easily shift for $1 \mathrm{~h}$. This criterion provides the basis of modelling for DR costs.

The same model is used to calculate the following parameters which include average flexibility per house out of all 145 houses for all the shifting intervals $(5 \mathrm{~min} . .600 \mathrm{~min}$ ), the average of all these 
shifting intervals which is $170 \mathrm{~min}$ and the average compensation and average flexibility as given in Table 4 below. Average compensation is expressed as percent of the annual electricity bill.

Table 4. Average model for compensation.

\begin{tabular}{cl}
\hline Average Flexibility per House & $11.8 \%$ \\
\hline Average Flexibility Duration & $170 \mathrm{~min}$ \\
\hline Average Compensation (asked by the customers) & $7.50 \%$ \\
\hline
\end{tabular}

To calculate the compensation cost, it is proposed that the customers will receive a certain percentage of the energy cost only for the load they are WTS for a certain shifting duration but not the full load or full energy consumption of the customer per day. For example if a customer has a total load of $10 \mathrm{~kW}$ and total energy consumption per day is $20 \mathrm{kWh}$ but he/she is WTS only $4 \mathrm{~kW}$ for a certain shifting duration (e.g., $30 \mathrm{~min}$ ), and this load consumes $8 \mathrm{kWh}$ energy, in this case only this $8 \mathrm{kWh}$ will be considered for the compensation, irrespective of the total energy consumption of this customer per day.

To accomplish our objective to calculate the compensation cost, firstly the total shiftable load is determined for each shifting duration (i.e., 5, 15, 30, 60, 180, 300, and $600 \mathrm{~min}$ ) and their energy consumption cost is calculated using Equation (5). In this equation $P_{i}$ is a certain load (e.g., electric stove/oven), $t_{i}$ is its operation duration (e.g., $2 \mathrm{~h}$ ), $C_{e}$ is the electricity price in $\mathrm{kWh}$ and $\mathrm{N}$ is the total number of appliances in a household. A flat rate of 6 cents $/ \mathrm{kWh}$ is considered to be a value of constant $C_{e}$ for whole day in these calculations [45].

$$
C_{\text {Energy }}=\frac{\sum_{n=1}^{N}\left(P_{i} \times t_{i}\right)}{1000} \times C_{e}
$$

The results are given in column 2 of Table 5. It is clear that the energy cost of the shifted load for smaller shifting duration is higher due to the fact that customers are WTS their critical loads only for smaller duration. Hence, the number of loads and the total shifted load will be high, leading to a higher energy cost of these loads for the smaller shifting duration and as the customers are WTS only non-critical load for large shifting interval, therefore the number of loads and total shifted load is less, so the energy cost is lower.

Then average percentage compensation which customers are WTA for a certain shifting duration is determined from survey results and is given in column 3 of Table 5. Finally, the compensation cost is calculated by using Equation (6) and is given in column 4 of Table 5.

$$
C C_{D R}=\frac{\sum_{n=1}^{N}\left(P_{i} \times t_{i}\right)}{1000} \times C_{e} \times \frac{\% C}{100}
$$

where $C C_{D R}$ is the compensation cost of $\mathrm{DR}$, and \%C is the percent compensation expected by the customers (determined from survey results and given in column 3 of Table 5).

Table 5. Compensation cost for each shifting interval.

\begin{tabular}{cccc}
\hline $\begin{array}{c}\text { Shift Interval } \\
(\mathbf{m i n})\end{array}$ & $\begin{array}{c}\text { Energy Cost of the } \\
\text { Shifted Load (€) }\end{array}$ & Average \% Compensation & $\begin{array}{c}\text { Average Compensation Cost } \\
(€ / \text { House/Shifting Interval) }\end{array}$ \\
\hline 5 & 1.925 & 0.22 & 0.0042 \\
15 & 1.662 & 0.66 & 0.011 \\
30 & 1.478 & 1.32 & 0.019 \\
60 & 1.206 & 2.65 & 0.032 \\
180 & 0.772 & 7.90 & 0.061 \\
300 & 0.432 & 13.23 & 0.057 \\
600 & 0.219 & 26.47 & 0.058 \\
\hline
\end{tabular}


Figure 5 shows the plot of average compensation cost for all shifting durations, it can be seen that the compensation cost calculated based on WTA from the customer survey has a logarithmic relationship with the shifting interval. It varies almost linearly in start, for small time intervals and then it is almost constant for large intervals. Although the average compensation cost (euro per shift interval) shown in Table 5 is very low compared to the daily electricity bill, the participation of customers in these programs will surely help to avoid complete interruption of electric supply or blackouts. Moreover, due to the low cost, it is a feasible and economical solution for the utility companies to implement it.

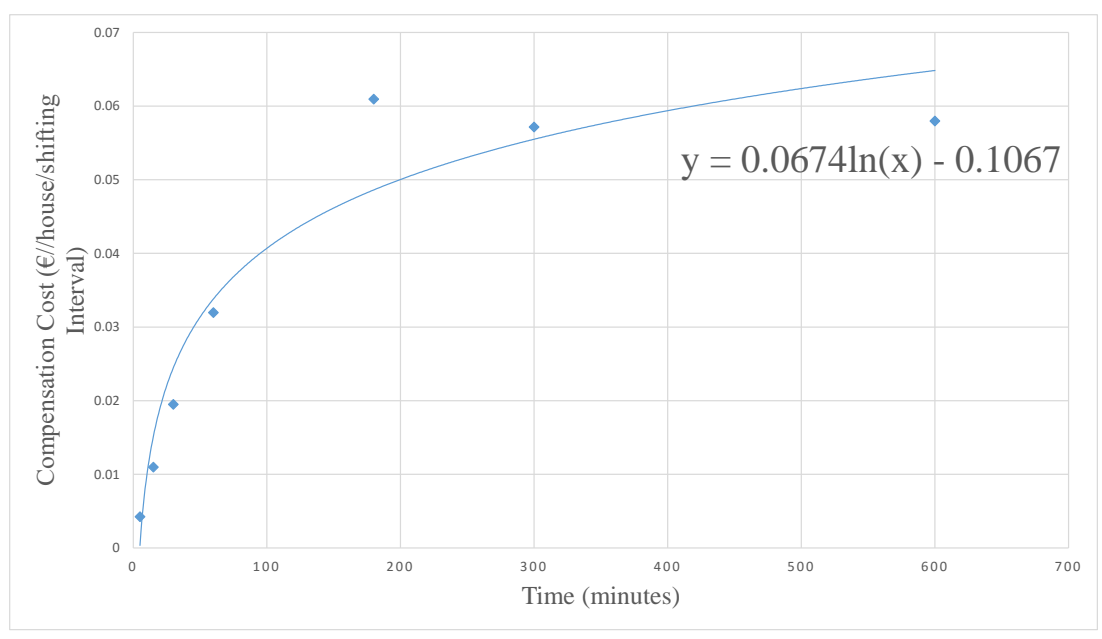

Figure 5. Average compensation cost of DR (€/house/shifting interval) vs. the shifting durations.

\subsection{Customers' Dependency Factor ' $d$ '}

Dependency of domestic customers on the electricity is determined from the survey and a parameter is defined as "the continuous electric power dependency factor" $d$ whose value may range from 0 to 1. In this study, the dependency factor, $d$ is calculated using Equation (7), which gives an idea about how much people are dependent on loads/appliances and for how much time they can postpone the operation of appliances [4].

$$
d=\frac{100 \%-\% \text { Reduction in Power Consumption due to load shifting }}{100 \%}
$$

The 0 value of the $d$ tells that $100 \%$ of the load can be shifted, whereas 1 represents $100 \%$ dependency of a certain customer on the loads and none of the appliances can be shifted. The $d$ for an individual house is calculated for the different load shifting intervals (from $0 \mathrm{~min}$ to $600 \mathrm{~min}$ ). Then average values of all the houses was calculated and summarized in Table 6 below. The results can also be seen in the bar graph in Figure 6. It is observed that the $d$ factor is low for smaller shift durations and increases linearly as the load shift interval increases.

Table 6. Dependency factor against shifting intervals.

\begin{tabular}{cc}
\hline Shift Duration (min) & Average $\boldsymbol{d}$ per House \\
\hline 5 & 0.1781 \\
15 & 0.2698 \\
30 & 0.3301 \\
60 & 0.4297 \\
180 & 0.6256 \\
300 & 0.7771 \\
600 & 0.8649 \\
\hline
\end{tabular}




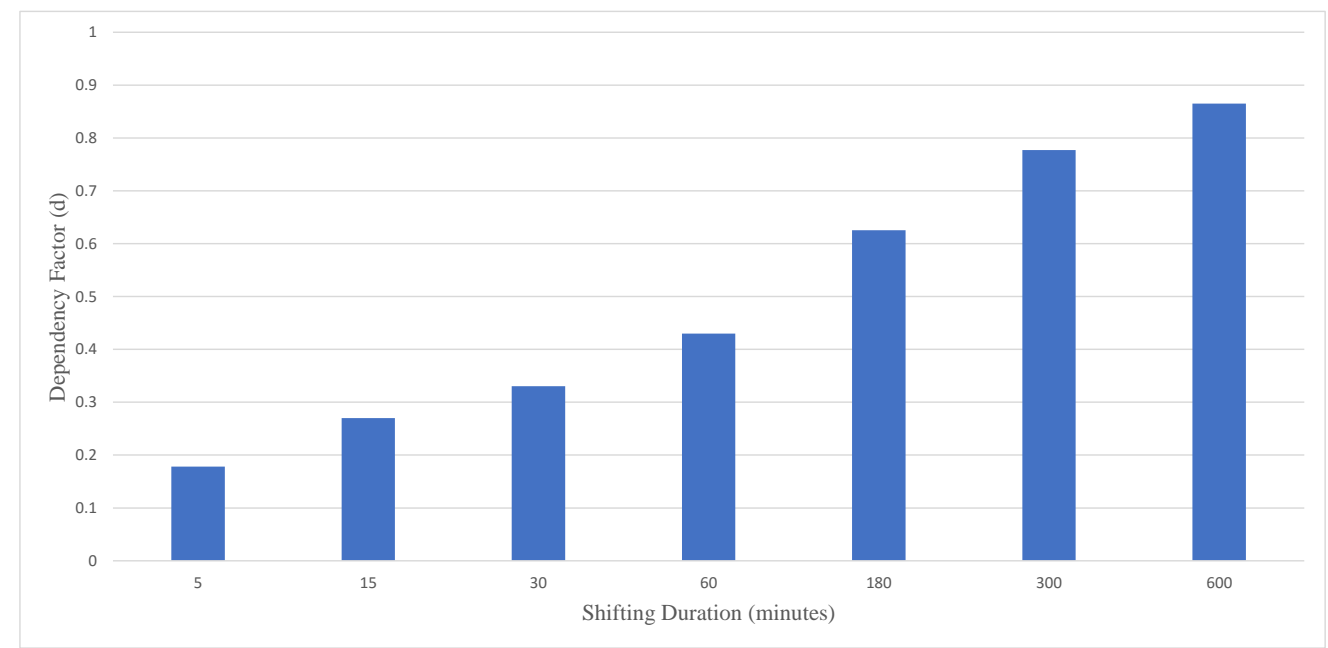

Figure 6. Average dependency factor vs. shifting interval.

\subsection{DR Cost Calculation Based on Dependency Factor d}

A macroeconomic approach was proposed for customers' outage costs in [46], the basic theory of this model is that "one hour of shift duration during the free time is equal to one non-working hour during the office hours" which employs that this one non-working hour will be equal to one hour salary/wage of the work. Therefore, using the same approach a model is developed for calculation of DR cost as a compensation for shifting [44]. The cost is calculated for each duration of time using the 8 given below.

$$
D R_{-} \operatorname{Cost}_{m e}=d \cdot \frac{t w}{P P}
$$

where $d$ is the dependency factor for continuous electric power determined in Equation (7). PP is the total peak power consumption in $\mathrm{kW}$ per each household, $t$ is the load shifting duration in hours and $w$ is the hourly wage in euros $(€)$. These variables are easy to find and use. Therefore, based on above equation the DR cost is calculated in Table 7 . Figure 7 shows the plot of DR cost for all shifting durations using average dependency factor $d$ per household.

Table 7. DR cost vs. shifting intervals.

\begin{tabular}{ccl}
\hline Shift Duration (min) & Average $d$ per House & DR Cost $(€ / \mathbf{k W})$ \\
\hline 5 & 0.1781 & 0.0117 \\
15 & 0.2698 & 0.0530 \\
30 & 0.3301 & 0.1297 \\
60 & 0.4297 & 0.3377 \\
180 & 0.6256 & 1.4750 \\
300 & 0.7771 & 3.0537 \\
600 & 0.8649 & 6.7975 \\
\hline
\end{tabular}

It is clear from the above Table 7 and Figure 7 that the DR cost is as low as a few cents $/ \mathrm{kW}$ for small shift intervals up to $30 \mathrm{~min}$, whereas this cost increase significantly as the shifting interval increases. Therefore, from this model, it is clear that it is more economical to shift loads for small intervals and if there is a need, the loads can be requested to be shifted again. Usually, the peak hours last between $2-3 \mathrm{~h}$ and the cost can be as high as $1.475 € / \mathrm{kW}$ for this interval as shown in Figure 7 . This model seems to be more attractive for customers and does not look feasible or economical for utility companies. 


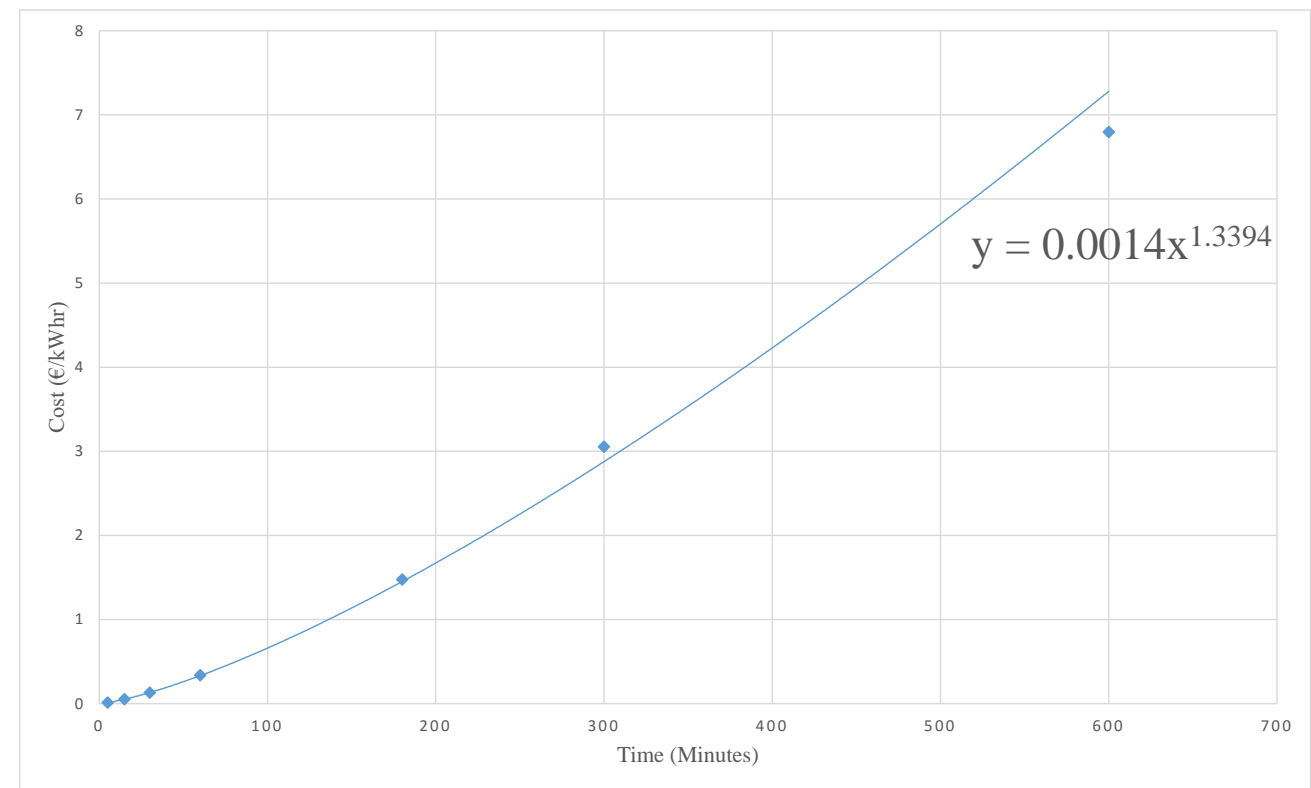

Figure 7. DR cost $(€ / \mathrm{kW})$ based on macroeconomic model vs. the shifting intervals.

\section{Comparison between CIC and DR Compensation Cost}

As explained in Section 2.3, the CIC cost and DR cost are correlated. A survey was conducted in Helsinki by a colleague to assess the CICs using direct approach and WTA and willingness to pay (WTP) criteria [4,44]. As the weather condition of Finland is very harsh during the winter time, most of the peak demand occur during this time due to heating system. So, keeping in view this scenario customers were asked to either accept certain outage duration 1-3 h (WTA) or they were asked to pay certain amount to get continuous electric supply (WTP). The direct losses faced by the customers due to interruptions were also evaluated in this study, and termed as CIC direct worth $\left(C I C_{D W}\right)$ estimation. By the analysis of the data gathered using these approaches the CIC cost was calculated by different methods and is given in Table 8 below, which is compared with the DR costs calculated in Tables 5 and 7 , and the comparison is made for $1 \mathrm{~h}$ and $3 \mathrm{~h}$ durations. The values for $C_{D C} C_{D W}$, WTA and WTP are used from literature [4,44]. As it is obvious from the results in Table 8, the DR costs are much lower than the interruption costs and this is very favorable for utility companies. It is also in the best interests of customers that they will be paid a compensation without a complete blackout. However, customers may have to sacrifice some of their comforts, leisure activities, and flexibility of using appliances. Hence, implementation of DR programs is in the best interests of all stake holders.

Table 8. Comparison of DR cost with CIC for household customers.

\begin{tabular}{cccccc}
\hline & \multicolumn{4}{c}{ CIC Cost $(€ / \mathbf{k W})$} & \multicolumn{2}{c}{ DR Cost } \\
\hline Outage Duration & $C I C_{D W}$ & WTA & WTP & $C_{D R}(€)$ & DR-Cost $_{m e}(€ / \mathrm{kW})$ \\
\hline $1 \mathrm{~h}$ & 7.8 & 12.12 & 1.2 & 0.031 & 0.337 \\
\hline $3 \mathrm{~h}$ & 23.4 & 36.36 & 3.6 & 0.060 & 1.475 \\
\hline
\end{tabular}

\section{Conclusions}

Peak electricity demands result in increase in electricity prices, overloading of power lines, and sometimes interruption of electric supply to the customers. One of the widely accepted solutions is DR, in which customers are asked to shift some of their loads to off-peak hours. In this paper, an econometric study based on customer survey is done to estimate the DR costs from a customer 
perspective. In this study, 145 residential customers participated. The analysis of survey results represents the potential of DR for residential customers and determines the available power flexibility of various daily use appliances. As the participation in DR programs may compromise the customer comfort levels and their freedom to use appliances, as well as their loss of leisure time, therefore the DR costs are determined by incorporating these factors while asking customers the percentage compensation they are WTA on their electricity bills in return.

Two methods are used to calculate the DR costs: willingness of customers to accept a percentage compensation (WTA Method), and a macroeconomic model which considers the dependency factor of customers on loads and hourly wage. A linear mathematical model is presented based on both techniques. It is found that the average percentage compensation asked by the customers for a three-hour shifting of loads is $7.90 \%$ of the electricity bill for those loads which are shifted. The compensation cost paid by the utility company for a three-hour shifting duration is estimated as 6 cents per house per shifting event only. The average dependency of a house for three hours on loads is determined to be 0.63 and the DR cost calculated is $1.47 \mathrm{euro} / \mathrm{kw}$, which is much higher than the results obtained by WTA technique. The calculated DR costs are compared with CICs in Table 8, due to their relevance in terms of consequences during the unavailability of electric supply.

This study proves that DR costs are much less than the interruption costs experienced by customers and hence in the best interests of all the stake holders, i.e., customers, utility company, and transmission company.

Supplementary Materials: The following are available online at http:/ /www.mdpi.com/1996-1073/12/9/1617 /s1.

Author Contributions: M.L. and M.S. conceived the idea M.S. designed the model, conducted the survey, analyzed the data and made the calculations. M.S. and G.A.H. wrote the manuscript in consultation with M.L. All authors provided critical feedback and helped to shape the manuscript.

Funding: This research was funded by Aalto University School of Electrical Engineering, Finland, through project number 9170303.

Conflicts of Interest: The authors declare no conflict of interest. 


\section{Appendix A}

Appendix A.1. Survey Results

Table A1. Willingness to Shift certain Appliances against Shifting Intervals

\begin{tabular}{|c|c|c|c|c|c|c|c|c|c|}
\hline Appliance Name & Ownership & NWS & 5 min Shift & 15 min Shift & 30 min Shift & 60 min Shift & 180 min Shift & 300 min Shift & 600 min Shift \\
\hline Domestic Heater & $55 \%$ & $17.50 \%$ & $10 \%$ & $10 \%$ & $15 \%$ & $17.50 \%$ & $17.50 \%$ & $10 \%$ & $2.50 \%$ \\
\hline Sauna Stove & $53 \%$ & $5.20 \%$ & $2.60 \%$ & $2.60 \%$ & $12.99 \%$ & $23.37 \%$ & $15.88 \%$ & $11.68 \%$ & $25.97 \%$ \\
\hline Domestic Hot Water & $46 \%$ & $12.12 \%$ & $18.18 \%$ & $12.12 \%$ & $9.09 \%$ & $21.21 \%$ & $12.12 \%$ & $7.58 \%$ & $7.58 \%$ \\
\hline Electric Cooker & $90 \%$ & $24.50 \%$ & $11.45 \%$ & $12.21 \%$ & $19.84 \%$ & $22.90 \%$ & $6.87 \%$ & $1.52 \%$ & $0.76 \%$ \\
\hline Air Conditioning & $41 \%$ & $6.67 \%$ & $16.67 \%$ & $13.33 \%$ & $13.33 \%$ & $18.33 \%$ & $13.33 \%$ & $8.33 \%$ & $10 \%$ \\
\hline Dish Washer & $70 \%$ & $2.97 \%$ & $1.98 \%$ & $1 \%$ & $4.95 \%$ & $12.87 \%$ & $31.68 \%$ & $21.78 \%$ & $22.77 \%$ \\
\hline Washing Machines & $83 \%$ & $4.17 \%$ & $4.17 \%$ & $0.83 \%$ & $3.33 \%$ & $29.16 \%$ & $23.33 \%$ & $15.83 \%$ & $19.16 \%$ \\
\hline Clothes Dryer & $81 \%$ & $3.42 \%$ & $4.27 \%$ & $0.85 \%$ & $2.56 \%$ & $29.05 \%$ & $23.08 \%$ & $16.23 \%$ & $20.51 \%$ \\
\hline AV Systems & $79 \%$ & $35 \%$ & $17.54 \%$ & $8.71 \%$ & $6.14 \%$ & $9.65 \%$ & $11.40 \%$ & $3.51 \%$ & $7.89 \%$ \\
\hline Desktop Computer & $78 \%$ & $43.36 \%$ & $26.55 \%$ & $5.31 \%$ & $7.08 \%$ & $7.08 \%$ & $3.54 \%$ & $3.54 \%$ & $3.54 \%$ \\
\hline Coffee Machine & $65 \%$ & $28.72 \%$ & $29.79 \%$ & $9.57 \%$ & $9.58 \%$ & $7.45 \%$ & $7.45 \%$ & $3.19 \%$ & $4.26 \%$ \\
\hline Electric Iron & $73 \%$ & $13.21 \%$ & $12.26 \%$ & $8.50 \%$ & $9.43 \%$ & $15.09 \%$ & $10.38 \%$ & $12.26 \%$ & $18.87 \%$ \\
\hline Cooking Accessories & $79 \%$ & $26.08 \%$ & $20.87 \%$ & $11.30 \%$ & $15.65 \%$ & $10.43 \%$ & $7.83 \%$ & $4.35 \%$ & $3.47 \%$ \\
\hline Vacuum Cleaner & $83 \%$ & $7.50 \%$ & $4.17 \%$ & $5.83 \%$ & $11.66 \%$ & $20 \%$ & $19.16 \%$ & $13.33 \%$ & $18.33 \%$ \\
\hline MW Oven & $86 \%$ & $32 \%$ & $24 \%$ & $12 \%$ & $16.80 \%$ & $4 \%$ & $6.40 \%$ & $1.60 \%$ & $3.20 \%$ \\
\hline
\end{tabular}


Appendix A.2. Flexibility of Individual Appliances

Table A2. Average percentage flexibility of appliances.

\begin{tabular}{cccccccc}
\hline Shifting Intervals (min) & $\mathbf{5}$ & $\mathbf{1 5}$ & $\mathbf{3 0}$ & $\mathbf{6 0}$ & $\mathbf{1 8 0}$ & $\mathbf{3 0 0}$ & $\mathbf{6 0 0}$ \\
\hline Domestic Heater & $83 \%$ & $73 \%$ & $63 \%$ & $48 \%$ & $30 \%$ & $13 \%$ & $3 \%$ \\
Sauna Stove & $95 \%$ & $92 \%$ & $90 \%$ & $77 \%$ & $53 \%$ & $38 \%$ & $26 \%$ \\
Domestic Hot water tank & $88 \%$ & $70 \%$ & $58 \%$ & $48 \%$ & $27 \%$ & $15 \%$ & $8 \%$ \\
Electric Cooker/Oven & $76 \%$ & $64 \%$ & $52 \%$ & $32 \%$ & $9 \%$ & $2 \%$ & $1 \%$ \\
Air Conditioning & $93 \%$ & $77 \%$ & $63 \%$ & $50 \%$ & $32 \%$ & $18 \%$ & $10 \%$ \\
Dish Washer & $97 \%$ & $95 \%$ & $94 \%$ & $89 \%$ & $76 \%$ & $45 \%$ & $23 \%$ \\
Washing Machine & $96 \%$ & $92 \%$ & $91 \%$ & $88 \%$ & $58 \%$ & $35 \%$ & $19 \%$ \\
Clothes Dryer & $97 \%$ & $92 \%$ & $91 \%$ & $89 \%$ & $60 \%$ & $37 \%$ & $21 \%$ \\
Tv/Video/DVD/Music System & $65 \%$ & $47 \%$ & $39 \%$ & $32 \%$ & $23 \%$ & $11 \%$ & $8 \%$ \\
Desktop Computer & $57 \%$ & $30 \%$ & $25 \%$ & $18 \%$ & $11 \%$ & $7 \%$ & $4 \%$ \\
Coffee Machine & $71 \%$ & $41 \%$ & $32 \%$ & $22 \%$ & $15 \%$ & $7 \%$ & $4 \%$ \\
Electric Iron & $87 \%$ & $75 \%$ & $66 \%$ & $57 \%$ & $42 \%$ & $31 \%$ & $19 \%$ \\
Electric Kettle/Mixer/Blender & $74 \%$ & $53 \%$ & $42 \%$ & $26 \%$ & $16 \%$ & $8 \%$ & $3 \%$ \\
Vacuum Cleaner & $93 \%$ & $88 \%$ & $83 \%$ & $71 \%$ & $51 \%$ & $32 \%$ & $18 \%$ \\
Microwave Oven & $68 \%$ & $44 \%$ & $32 \%$ & $15 \%$ & $11 \%$ & $5 \%$ & $3 \%$ \\
Average Flexibility & $\mathbf{8 3} \%$ & $\mathbf{6 9} \%$ & $\mathbf{6 1} \%$ & $\mathbf{5 1} \%$ & $\mathbf{3 4 \%}$ & $\mathbf{2 0} \%$ & $\mathbf{1 1 \%}$ \\
\hline
\end{tabular}

\section{References}

1. Safdar, M.; Ahmad, M.; Hussain, A.; Lehtonen, M. Optimized residential load scheduling under user defined constraints in a real-time tariff paradigm. In Proceedings of the 2016 17th International Scientific Conference on Electric Power Engineering (EPE), Prague, Czech Republic, 16-18 May 2016; pp. 1-6.

2. Strbac, G. Demand side management: Benefits and challenges. Energy Policy 2008, 36, 4419-4426. [CrossRef]

3. Palmer, J.; Terry, N.; Kane, T.; Firth, S.; Hughes, M.; Pope, P.; Young, J.; Knight, D.; Godoy-Shimizu, D. Further Analysis of the Household Electricity Use Survey Electrical Appliances at Home: Tuning in to Energy Saving. Cambridge Architectural Research Limited. Technical Report. 2012. Available online: https:/ / assets.publishing.service.gov.uk/government/uploads/system/uploads/attachment_da ta/file/275484/electricity_survey_2_tuning_in_to_energy_saving.pdf (accessed on 27 April 2019).

4. Küfeoğlu, S.; Lehtonen, M. Comparison of different models for estimating the residential sector customer interruption costs. Electr. Power Syst. Res. 2015, 122, 50-55. [CrossRef]

5. Wang, S.; Xue, X.; Yan, C. Building power demand response methods toward smart grid. HVAC\&R Res. 2014, 20, 665-687.

6. Kostková, K.; Omelina, L'.; Kyčina, P.; Jamrich, P. An introduction to load management. Electr. Power Syst. Res. 2013, 95, 184-191. [CrossRef]

7. Bashir Ahmad, A.; Pourakbari Kasmaei, M.; Safdarian, A.; Lehtonen, M. Matching of Local Load with On-Site PV Production in a Grid-Connected Residential Building. Energies 2018, 11, 2409. [CrossRef]

8. Kousksou, T.; Bruel, P.; Jamil, A.; Rhafiki, T.E.; Zeraouli, Y. Energy storage: Applications and challenges. Sol. Energy Mater. Sol. Cells 2014, 120, 59-80. [CrossRef]

9. Mohsenian-Rad, A.H.; Wong, V.W.; Jatskevich, J.; Schober, R.; Leon-Garcia, A. Autonomous demand-side management based on game-theoretic energy consumption scheduling for the future smart grid. IEEE Trans. Smart Grid 2010, 1, 320-331. [CrossRef]

10. Bashir Ahmad, A.; Pourakbari-Kasmaei, M.; Contreras, J.; Lehtonen, M. A novel energy scheduling framework for reliable and economic operation of islanded and grid-connected microgrids. Electr. Power Syst. Res. 2019, 171, 85-96. [CrossRef]

11. Khodaei, A.; Shahidehpour, M.; Bahramirad, S. SCUC with hourly demand response considering intertemporal load characteristics. IEEE Trans. Smart Grid 2011, 2, 564-571. [CrossRef]

12. Albadi, M.H.; El-Saadany, E.F. Demand response in electricity markets: An overview. In Proceedings of the 2007 IEEE Power Engineering Society General Meeting, Tampa, FL, USA, 24-28 June 2007; pp. 1-5.

13. López, M.; De La Torre, S.; Martín, S.; Aguado, J. Demand-side management in smart grid operation considering electric vehicles load shifting and vehicle-to-grid support. Int. J. Electr. Power Energy Syst. 2015, 64, 689-698. [CrossRef] 
14. Siano, P. Demand response and smart grids-A survey. Renew. Sustain. Energy Rev. 2014, 30, 461-478. [CrossRef]

15. Earle, R.; Faruqui, A. Toward a new paradigm for valuing demand response. Electr. J. 2006, 19, $21-31$. [CrossRef]

16. Soares, A.; Gomes, Á.; Antunes, C.H. Categorization of residential electricity consumption as a basis for the assessment of the impacts of demand response actions. Renew. Sustain. Energy Rev. 2014, 30, 490-503. [CrossRef]

17. Vivekananthan, C.; Mishra, Y.; Ledwich, G.; Li, F. Demand response for residential appliances via customer reward scheme. IEEE Trans. Smart Grid 2014, 5, 809-820. [CrossRef]

18. Shimomura, Y.; Nemoto, Y.; Akasaka, F.; Chiba, R.; Kimita, K. A method for designing customer-oriented demand response aggregation service. CIRP Ann. 2014, 63, 413-416. [CrossRef]

19. Haider, H.T.; See, O.H.; Elmenreich, W. A review of residential demand response of smart grid. Renew. Sustain. Energy Rev. 2016, 59, 166-178. [CrossRef]

20. Torriti, J. Price-based demand side management: Assessing the impacts of time-of-use tariffs on residential electricity demand and peak shifting in Northern Italy. Energy 2012, 44, 576-583. [CrossRef]

21. Nikzad, M.; Mozafari, B. Reliability assessment of incentive- and priced-based demand response programs in restructured power systems. Int. J. Electr. Power Energy Syst. 2014, 56, 83-96. [CrossRef]

22. Wu, Z.; Zhou, S.; Li, J.; Zhang, X.P. Real-time scheduling of residential appliances via conditional risk-at-value. IEEE Trans. Smart Grid 2014, 5, 1282-1291. [CrossRef]

23. Alberini, A.; Filippini, M. Response of residential electricity demand to price: The effect of measurement error. Energy Econ. 2011, 33, 889-895. [CrossRef]

24. Yoon, J.H.; Bladick, R.; Novoselac, A. Demand response for residential buildings based on dynamic price of electricity. Energy Build. 2014, 80, 531-541. [CrossRef]

25. Wang, Y.; Mao, S.; Nelms, R.M. Distributed online algorithm for optimal real-time energy distribution in the smart grid. IEEE Internet Things J. 2014, 1, 70-80. [CrossRef]

26. Ozturk, Y.; Senthilkumar, D.; Kumar, S.; Lee, G. An intelligent home energy management system to improve demand response. IEEE Trans. Smart Grid 2013, 4, 694-701. [CrossRef]

27. Setlhaolo, D.; Xia, X.; Zhang, J. Optimal scheduling of household appliances for demand response. Electr. Power Syst. Res. 2014, 116, 24-28. [CrossRef]

28. Kinhekar, N.; Padhy, N.P.; Gupta, H.O. Multiobjective demand side management solutions for utilities with peak demand deficit. Int. J. Electr. Power Energy Syst. 2014, 55, 612-619. [CrossRef]

29. Di Giorgio, A.; Liberati, F. Near real time load shifting control for residential electricity prosumers under designed and market indexed pricing models. Appl. Energy 2014, 128, 119-132. [CrossRef]

30. Pallonetto, F.; Rosa, M.D.; Milano, F.; Finn, D.P. Demand response algorithms for smart-grid ready residential buildings using machine learning models. Appl. Energy 2019, 239, 1265-1282. [CrossRef]

31. Gyamfi, S.; Krumdieck, S.; Urmee, T. Residential peak electricity demand response-Highlights of some behavioural issues. Renew. Sustain. Energy Rev. 2013, 25, 71-77. [CrossRef]

32. Hamidi, V.; Li, F.; Robinson, F. Demand response in the UK's domestic sector. Electr. Power Syst. Res. 2009, 79, 1722-1726. [CrossRef]

33. Qdr, Q. Benefits of Demand Response in Electricity Markets and Recommendations for Achieving Them; US Department Energy: Washington, DC, USA, 2006.

34. Jordehi, A.R. Optimisation of demand response in electric power systems, a review. Renew. Sustain. Energy Rev. 2019, 103, 308-319. [CrossRef]

35. Palmer, J.; Terry, N.; Firth, S.; Kane, T.; Godoy-Shimizu, D.; Pope, P. Energy Use at Home: Models, Labels and Unusual Appliances. Available online: https://www.gov.uk/government/publications/models-labels -and-unusual-appliances (accessed on 27 April 2019).

36. Kariuki, K.; Allan, R. Assessment of customer outage costs due to electric service interruptions: Residential sector. IEE Proc.-Gener. Transm. Distrib. 1996, 143, 163-170. [CrossRef]

37. Billinton, R.; Chan, E.; Wacker, G. Probability distribution approach to describe customer costs due to electric supply interruptions. IEE Proc.-Gener. Transm. Distrib. 1994, 141, 594-598. [CrossRef]

38. Wacker, G.; Billinton, R. Customer cost of electric service interruptions. Proc. IEEE 1989, 77, 919-930. [CrossRef] 
39. Nasseri, I.; Fotuhi-Firuzabad, M. Modeling the Customer Outage Cost; Introduction of New Fuzzy Modeling in Comparison with Customary Average Modeling. Available online: https:/ / www.researchgate.net/publication/229022433_Modeling_the_Customer_Outage_Cost_Int roduction_of_New_Fuzzy_Modeling_in_Comparison_With_Customary_Average_Modeling (accessed on 27 April 2019).

40. Praktiknjo, A.J. Stated preferences based estimation of power interruption costs in private households: An example from Germany. Energy 2014, 76, 82-90. [CrossRef]

41. Morrissey, K.; Plater, A.; Dean, M. The cost of electric power outages in the residential sector: A willingness to pay approach. Appl. Energy 2018, 212, 141-150. [CrossRef]

42. Billinton, R. Methods to Consider Customer Interruption Costs in Power System Analysis: Task Force, Task Force (TF) 38.06. 01; Cigré Technical Brochure: Paris, France, 2001.

43. Küfeoglu, S.; Lehtonen, M. Evaluation of Power Outage Costs for Industrial and Service Sectors in Finland. In Proceedings of the 22nd International Conference on Electricity Distribution (CIRED), Stockholm, Sweden, 10-13 June 2013.

44. Küfeoğlu, S. Economic Impacts of Electric Power Outages and Evaluation of Customer Interruption Costs. Ph.D. Thesis, Aalto University, Espoo, Finland, 2015.

45. Finland, H. Our Electrical Product for You (in Cents per Kilowatt-Hour). Available online: https://www4.h elen.fi/Sahkokauppa/MakeContract.aspx (accessed on 27 April 2019).

46. Praktiknjo, A.J.; Hähnel, A.; Erdmann, G. Assessing energy supply security: Outage costs in private households. Energy Policy 2011, 39, 7825-7833. [CrossRef]

(C) 2019 by the authors. Licensee MDPI, Basel, Switzerland. This article is an open access article distributed under the terms and conditions of the Creative Commons Attribution (CC BY) license (http:/ / creativecommons.org/licenses/by/4.0/). 